\title{
Changes in the plasma clearance and protein binding of carbenoxolone with age, and their possible relationship with adverse drug effects
}

\author{
M. J. HAYES, MARGARET SPRACKLING, AND M. J. S. LANGMAN ${ }^{1}$
}

From the Departments of Therapeutics and Medicine, University of Nottingham Medical School, Nottingham

SUMMARY Comparison by equilibrium dialysis of plasma protein binding sites for carbenoxolone in people under 40 years of age and in people over 65 years of age showed that the number of binding sites was reduced in the elderly and that this fall was associated with a reduction in plasma albumin levels. Although carbenoxolone has some aldosterone-like effects, these properties could not be shown to be due to displacement of aldosterone from its protein binding sites by competitive protein binding of carbenoxolone. Single doses of carbenoxolone were found to be removed considerably more slowly from the plasma of elderly individuals than from the young. The results of these three series of experiments suggest that the side-effects of carbenoxolone in the elderly may in part be caused by reduced protein binding, leaving more free drug in the active unbound form, and in part by reduced hepatic clearance mechanisms.

There is now ample proof that carbenoxolone sodium is an effective drug in the treatment of gastric ulcer, but its use is limited by its tendency to cause side-effects, predominantly of salt and water retention. Such effects are especially prominent in those who have cardiorespiratory disease, and in the elderly. Carbenoxolone is a highly protein bound drug (Parke and Lindup, 1973) and this may be reduced in the elderly, as is the plasma binding capacity of several drugs, notably warfarin and phenytoin (Hayes et al., 1974a, b). Such changes could make more free drug available to exert its metabolic effects and, therefore, could explain at least part of the undue liability of elderly people to adverse reactions which are a natural consequence of the mode of action of carbenoxolone.

Two other mechanisms which could lead to an increased frequency of side-effects in the elderly include diminished removal by the liver and any tendency to displace aldosterone from binding sites on plasma proteins. Carbenoxolone is almost entirely removed from the circulation by conjugation in the liver to form the glucuronide (Parke et al., 1972) and reduced hepatic activity could clearly

\footnotetext{
${ }^{1}$ Address for reprint requests: Professor M. J. S. Langman, Department of Therapeutics, City Hospital, Nottingham, NG5 1 PB.

Received for publication 30 June 1977
}

impair this mechanism. The sodium and water retaining and occasional kaliuretic effects of carbenoxolone resemble the actions of aldosterone, and the side-effects (and also, unfortunately, the clinical ulcer-healing activity of the drug) are abolished by treatment with spironolactone (Doll et al., 1968). This aldosterone-like activity of carbenoxolone could be due to preferential binding of carbenoxolone to plasma proteins, thus displacing bound and inactive aldosterone.

\section{Methods}

INDIVIDUALS STUDIED

Two groups were investigated. The first consisted of healthy volunteer hospital staff who were all under the age of 40 years, and the second was composed of people who were all over 65 years old and who were resident in geriatric hospitals in Nottingham. At the time of the study all the individuals were apparently in good health, none, except four of the elderly, was receiving any drug treatment and all had normal blood urea, electrolyte, and haemoglobin levels for their age (Caird, 1973).

PROTEIN BINDING STUDIES

Citrated plasma was diluted 1:3 with Tyrode's solution and $1 \mathrm{ml}$ aliquots were placed in Visking 
sacs and dialysed for 36 hours at $4^{\circ} \mathrm{C}$ against $5 \mathrm{ml}$ calcium-free Tyrode's solution to which tritiated carbenoxolone had been added. Duplicate plasma samples were exposed to each of seven different drug concentrations ranging from 50 to $400 \mu \mathrm{mol} / 1$ and at the end of dialysis carbenoxolone was measured in the two dialysis compartments. Control experiments with carbenoxolone-Tyrode solution on the outside and Tyrode solution on the inside of the sac were included in the experiments and showed that equilibrium was achieved by 36 hours. Aliquots of the plasma and Tyrode solution were assayed for radioactivity using a Beckman LS-100 liquid scintillation counter. Bound concentrations of carbenoxolone were calculated by the subtraction of the free concentration remaining in the outer Tyrode solution from the total concentration measured in the plasma. Drug binding to the Visking membrane proved to be negligible. Any protein leakage through the sacs was detected by analysing a sample of the post-dialysis Tyrode solution using the Folin-phenol technique adapted for the autoanalyser (Lowry et al., 1951), and contaminated samples were discarded. Binding data were analysed by the Rosenthal plot technique (Rosenthal, 1967). This allows the maximum quantity of drug bound per unit of plasma to be calculated together with the association constant. The equation used can be expressed in the general form:

$$
\frac{\mathrm{r}}{\mathrm{D}}=\mathrm{NK}-\mathrm{rK}
$$

where $r=$ moles of drug bound, $D=$ free drug concentration, $\mathrm{K}=$ association constant, and $\mathrm{N}=$ number of binding sites.

\section{ALDOSTERONE DISPLACEMENT}

Tritiated aldosterone at a concentration of 270 $\mu \mathrm{mol} / \mathrm{l}$ was added to the test plasma and then $0.5 \mathrm{ml}$ undiluted plasma was dialysed against $5 \mathrm{ml}$ Tyrode solution for 36 hours. Duplicate plasma samples were exposed to carbenoxolone in concentrations of 16 , 81,325 , and $651 \mu \mathrm{mol} / 1$ in these experiments and the proportions of tritiated aldosterone remaining bound to the different plasma samples were then compared.

CARBENOXOLONE CLEARANCE FROM PLASMA

Single doses of $300 \mathrm{mg}$ carbenoxolone sodium were administered orally to the two groups of young and elderly individuals. The drug was known to have a long half-life, and preliminary experiments showed that the peak carbenoxolone plasma level did not occur until two hours after drug ingestion.

Seven blood samples were therefore usually collected from each individual, at the start of the experiment and at 2, 4, 8, 12, 24, and 36 hours after drug ingestion, and in no subject were less than six samples obtained. Analyses of the carbenoxolone concentrations detectable in the plasma were then made using a gas-chromatographic technique (Rhodes and Wright, 1974), and the half-life, volume of distribution, and clearance in each individual were calculated.

The removal rate of a drug from plasma can be obtained by the formula:

$$
\mathrm{Cn}_{\mathrm{t}}=\mathrm{Cn}_{\mathrm{o}} \cdot \mathrm{e}^{-\mathrm{kt}}
$$

where $\mathrm{t}=$ time, $\mathrm{Cn}_{\mathrm{t}}=$ carbenoxolone concentration, $\mathrm{Cn}_{\mathrm{o}}=$ carbenoxolone concentration at $\mathrm{t}=0$, and $\mathrm{k}=$ logarithmic slope (elimination constant) of the curve.

Gibaldi et al. (1969) have shown that this equation can be applied to the terminal 'elimination' phase of a two-compartmental model and is independent of the route of administration. The terminal elimination phase after oral carbenoxolone administration was found to follow such a curve and the linear regression of log carbenoxolone on time was calculated and the values of $\mathrm{Cn}_{\mathrm{o}}$ and $\mathrm{k}$ obtained.

The volume of distribution ( $\mathrm{Vd}$ ) is given by

$$
\frac{\text { dose of drug administered }}{\text { Cno }},
$$

clearance $(\mathrm{Cl})$ by $\mathrm{Vd} \times \mathrm{k}$ and

half-life $\left(\mathrm{t} \frac{1}{2}\right)$ by $\frac{0.693}{k}$. The results were corrected on a body weight basis to allow for variations in body fluid compartments with weight.

\section{Results}

The carbenoxolone binding curve was non-linear (Figure), indicating the presence of more than one class of binding site. There was a high affinity site shown by the initial one-third of the curve and calculations have been restricted to this section as there were insufficient points in the graph to define accurately any of the additional sites. Table 1 compares the plasma albumin levels and the maximum binding capacity of the high affinity site. Both plasma albumin levels and the binding capacity were significantly lower in the elderly and there was a strong correlation between the two measurements $(r=0.85, \mathrm{P}<0.01)$.

Comparisons of the amount of aldosterone displaced from binding sites on plasma proteins in the young and old people showed only minor variations and Table 2 gives the figures obtained when carbenoxolone was used in a concentration of $651 \mu \mathrm{mol} / \mathrm{l}$, the level at which evidence of aldosterone displacement was greatest. Though there tended to be 


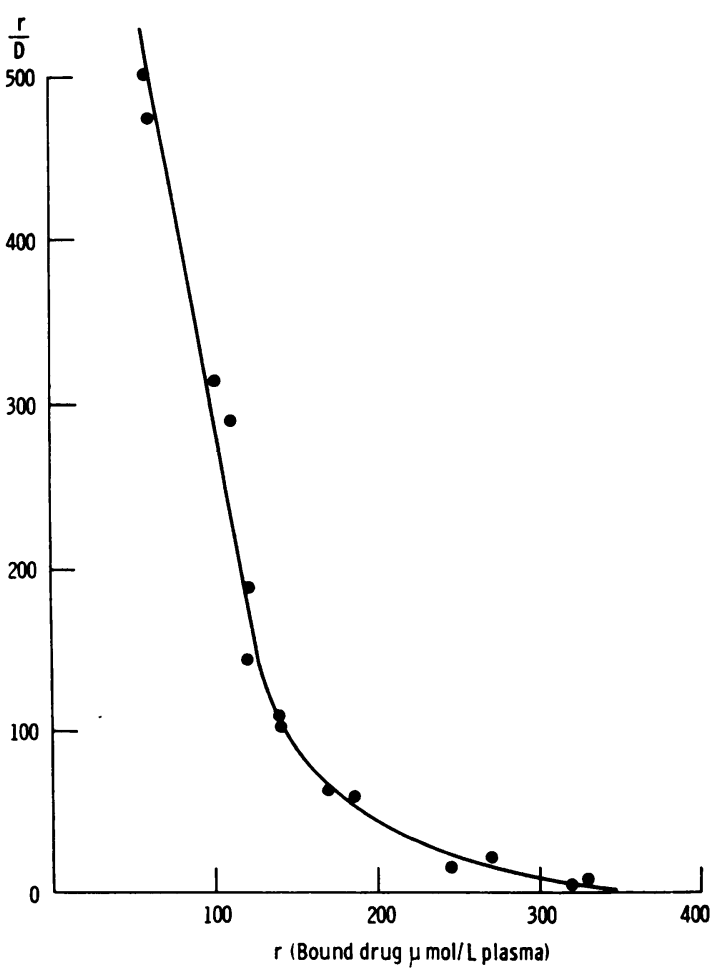

Figure Carbenoxolone binding curve.

slightly more free aldosterone, and slightly greater displacement of the hormone in the elderly than the young, the differences were small and statistically insignificant $(P>0.5)$.

The terminal plasma elimination phase of carbenoxolone appeared to follow an exponential curve, the overall correlation coefficient being $0.93 \pm 0.08$.

Data on the plasma clearance rates, drug half-life, and volumes of distribution are summarised in Table 3. Drug distribution in the body was virtually identical in the young and elderly, but plasma
Table 1 Serum albumin levels and available protein binding sites in young and old people

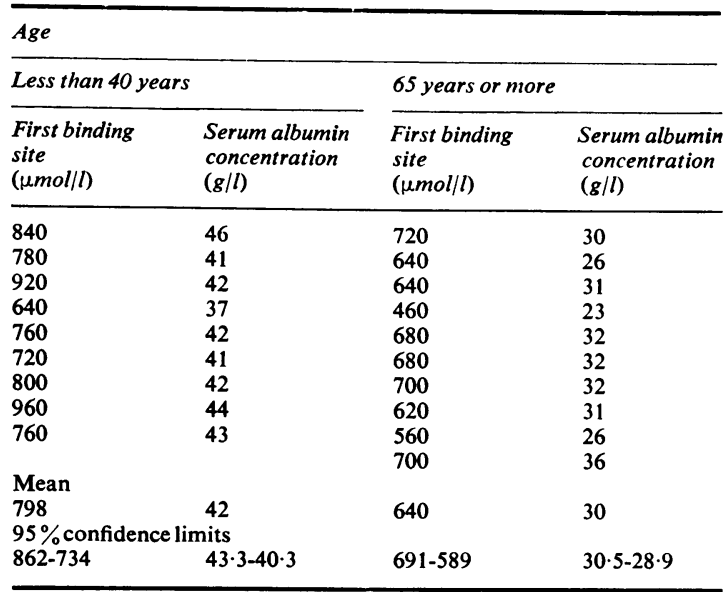

For the difference between the number of binding sites $t=3 \cdot 88, \mathrm{P}<$ 0.01 .

For the difference between the serum albumin level $t=9 \cdot 1, \mathrm{P}<0.001$.

Table 2 Aldosterone displacement from plasma proteins by carbenoxolone

\begin{tabular}{|c|c|c|c|c|}
\hline & \multicolumn{4}{|l|}{ Age } \\
\hline & \multicolumn{2}{|c|}{ Less than 40 years } & \multicolumn{2}{|c|}{65 years or more } \\
\hline & Mean & $\begin{array}{l}95 \% \\
\text { confidence } \\
\text { limits }\end{array}$ & Mean & $\begin{array}{l}95 \% \\
\text { confidence } \\
\text { limits }\end{array}$ \\
\hline \multirow[t]{2}{*}{$\begin{array}{l}\text { Percentage } \\
\text { aldosterone } \\
\text { displacement } \\
\text { Percentage free } \\
\text { aldosterone }\end{array}$} & $2 \cdot 5$ & $3 \cdot 3-1 \cdot 7$ & $3 \cdot 2$ & $4 \cdot 2-2 \cdot 2$ \\
\hline & $9 \cdot 0$ & $11 \cdot 5-6 \cdot 4$ & $13 \cdot 0$ & $16 \cdot 1-10 \cdot 0$ \\
\hline
\end{tabular}

For the differences between percentages of aldosterone displaced, in young and old people, $P>0 \cdot 1$. For the difference in free aldosterone, $\mathbf{P}<0.05$.

clearance rates in the elderly were markedly reduced. This difference was partly due to the especially slow clearance rates in some of the elderly people. Separate consideration of those elderly individuals who had clearance rates which were lower than any

Table 3 Carbenoxolone clearance, plasma half time, and drug volume of distribution in young and old people

\begin{tabular}{|c|c|c|c|c|c|c|}
\hline & \multicolumn{6}{|l|}{ Age } \\
\hline & \multicolumn{3}{|c|}{ Less than 40 years } & \multicolumn{3}{|c|}{65 years or more } \\
\hline $\begin{array}{l}\text { Range } \\
\text { Total no. } \\
\text { Mean }\end{array}$ & $\begin{array}{l}7 \cdot 84-3 \cdot 13 \\
9 \\
4 \cdot 72\end{array}$ & $\begin{array}{l}1127-620 \\
9 \\
980\end{array}$ & $\begin{array}{l}0 \cdot 143-0 \cdot 075 \\
9 \\
0 \cdot 105\end{array}$ & $\begin{array}{l}5 \cdot 01-1 \cdot 47 \\
15 \\
3 \cdot 28\end{array}$ & $\begin{array}{l}3346-737 \\
15 \\
1376\end{array}$ & $\begin{array}{l}0.152-0 \cdot 052 \\
15 \\
0.098\end{array}$ \\
\hline
\end{tabular}

$P<0.05$ for the difference in clearance rates.

$P<0.02$ for the difference in half lives. (Both Wilcoxon rank sum test). 
of those recorded in the younger people showed no obvious differences apart from age, and the results obtained from the four elderly people who were receiving other drugs showed no differences from the remainder.

Similar considerations applied to the values obtained for the half-lives. Taken overall, there were significant differences between the younger and older individuals for clearance $(P<0.05)$ and half-life $(P<0.02)$ when assessed by the Wilcoxon rank sum technique.

\section{Discussion}

No form of carbenoxolone is available for parenteral administration and, therefore, the drug must be given by mouth when studying its behaviour in the body. Carbenoxolone is rapidly absorbed from the gut and some $80 \%$ is present in the plasma two hours later (Downer et al., 1970). Carbenoxolone is virtually confined within the plasma, liver, and gastrointestinal tract (Parke, 1972), and there is no evidence for believing the absorption rates vary in the young and elderly. The rapid achievement of high plasma drug concentrations makes it probable that the major proportion of the drug does enter the plasma compartment and that continued absorption during the removal phase of the plasma time course is probably small.

The results obtained in this investigation showed that, in elderly people, the plasma binding capacity of the dominant site was reduced and that this related to a reduced plasma albumin concentration.

The exact mechanism for the age associated decline in plasma albumin has not been fully established. Woodford-Williams et al. (1965) related it to reduced mobility regardless of the cause, and they also found that the majority of people over the age of 70 years suffer some restriction of movement. Our elderly subjects were all over the age of 75 years and also had limited mobility; that would, at least in part, account for the lower albumin concentration found in this group.

Both the reduced carbenoxolone plasma binding and the greatly reduced drug clearance found in this investigation fit with the clinical observation that the side-effects of carbenoxolone tend to be more frequent in the elderly (Doll et al., 1962; Doll et al., 1965; Davies et al., 1974).

Carbenoxolone is very highly plasma protein bound (Parke and Lindup, 1973), mainly to plasma albumin. The reduction in binding sites in the elderly would thus be more likely to make more drug available in the free active form to exert its metabolic effects. Carbenoxolone is conjugated in the liver and excreted in the bile, and very little appears in the urine (Parke et al., 1972). Theoretically, if more free drug were available, then the proportion available for liver metabolism would be increased and so it might be expected that hepatic clearance rates would be increased in the elderly. In fact, the rate of drug removal was substantially reduced in old people, suggesting that either liver activity is itself reduced, or, less likely, that any enterohepatic circulation of carbenoxolone is increased. The findings of a reduced plasma protein binding with a reduced plasma clearance rate for carbenoxolone contrast with our earlier findings using diphenylhydantoin (Hayes et al., 1974b), where plasma binding was reduced and hepatic clearance rates increased. A similar dependence of plasma clearance on free drug concentration has been found to occur with warfarin (Yacobi et al., 1976).

Carbenoxolone is normally administered three times a day and, as the half-life was found to be about 19 hours, the drug would tend to accumulate in the plasma during treatment. As the removal rate is slower in old people, then dose for dose they would be expected to achieve higher plasma drug concentrations.

The mineralocorticoid-like activity of carbenoxolone could in theory be caused by displacement by carbenoxolone of aldosterone which is bound and inactive, to an intrinsic aldosterone-like activity, to competitive inhibition of the metabolic inactivation of aldosterone, or to changes in the degree of binding of aldosterone to receptors in the kidney. Our data give little or no support to the suggestion of aldosterone displacement from plasma proteins. This was slightly higher in the elderly than in the young, but only when very high levels of carbenoxolone were used, concentrations being much higher than those found during conventional treatment (Baron et al., 1975). Carbenoxolone treatment has, however, been shown to cause changes in the binding of aldosterone to subcellular fractions of kidney tissue (Humphrey et al., 1972) and a local tissue effect, therefore, seems likely as the main mechanism of the aldosterone-like activity of carbenoxolone.

We are grateful to Biorex Laboratories for supplies of carbenoxolone used in binding experiments, and to Miss P. A. Wright of Biorex Ltd. for the plasma carbenoxolone measurements.

\section{References}

Baron, J. H., Gribble, R. J. N., Rhodes, C., and Wright, P. A. (1975). Factors affecting the absorption of carbenoxolone in patients with peptic ulcer. In Fourth Symposium on Carbenoxolone Sodium, pp. 115-128. Edited by F. Avery Jones and D. V. Parke. Butterworths: London. 
Caird, F. I. (1973). Problems of interpretation of laboratory findings in the sld. British Medical Journal, 4, 348-351.

Davies, G. T., Rhodes, J., and Calcraft, B. J. (1974). Complications of carbenoxolone therapy. British Medical Journal, 3, 400-402.

Doll, R., Hill, I. D., and Hutton, C. F. (1965). Treatment of gastric ulcer with carbenoxolone sodium and oestrogens. Gut, 6, 19-24.

Doll, R., Hill, I. D., Hutton, C. F., and Underwood, D. J., II. (1962). Clinical trial of a triterpenoid liquorice compound in gastric and duodenal ulcer. Lancet, 2, 793-796.

Doll, R., Langman, M. J. S., and Shawdon, H. H. (1968). Treatment of gastric ulcer with carbenoxolone: antagonistic effect of spironolactone. Gut, 9, 42-45.

Downer, H. D., Galloway, R. W., Horwich, L., and Parke, D. V. (1970). The absorption and excretion of carbenoxolone in man. Journal of Pharmacy and Pharmacology, 22, 479-487.

Gibaldi, M., Nagashima, R., and Levy, G. (1969). Relationship between drug concentration in plasma or serum and amount of drug in the body. Journal of Pharmaceutical Sciences, 58, 193-197.

Hayes, M. J., Langman, M. J. S., and Short, A. H. (1974a). Changes in drug metabolism with increasing age. 1. Warfarin binding and plasma proteins. British Journal of Clinical Pharmacology, 2, 69-72.

Hayes, M. J., Langman, M. J. S., and Short, A. H. (1974b). Changes in drug metabolism with increasing age. 2. Phenytoin clearance and protein binding. British Journal of Clinical Pharmacology, 2, 73-79.

Horwich, L., and Galloway, R. (1965). Treatment of gastric ulceration with carbenoxolone sodium: clinical and radiological evaluation. British Medical Journal, 2, 1274-1277.
Humphrey, M. J., Lindup, W. E., Parke, D. V., and Chakraborty, J. (1972). The effect of carbenoxolone on the subcellular distribution of $(3 \mathrm{H})$ aldosterone in rat kidney (Abstract). Biochemical Journal, 130, 87P-88P.

Lowry, O. H., Rosebrough, N. J., Farr, A. L., and Randall, R. J. (1951). Protein measurement with the folin-phenol reagent. Journal of Biological Chemistry, 193, 265-275.

Parke, D. V. (1972). The biochemistry of carbenoxolone. In Carbenoxolone in Gastroenterology, pp. 19-32. Edited by Sir F. Avery Jones and F. M. Sullivan. Butterworths: London.

Parke, D. V., Hunt, T. C., and Iveson, P. (1972). The fate of $\left({ }^{14} \mathrm{C}\right)$ carbenoxolone in patients with gastric ulcer. Clinical Science, 43, 393-400.

Parke, D. V., and Lindup, W. E. (1973). Quantitative and qualitative aspects of the plasma protein binding of carbenoxolone, an ulcer healing drug. Annals of the New York Academy of Sciences, 226, 200-213.

Rhodes, C., and Wright, P. A. (1974). A gas chromatographic determination of carbenoxolone in human serum. Journal of Pharmacy and Pharmacology, 26, 894-898.

Rosenthal, H. E. (1967). A graphic method for the determination and presentation of binding parameters in a complex system. Analytical Biochemistry, 20, 525-532.

Woodford-Williams, E., Alvarez, A. S., Webster, D., Landless, B., and Dixon, M. P. (1965). Serum protein patterns in 'normal' and pathological ageing. Gerontologia, 10, 86-99.

Yacobi, A., Udall, J. A., and Levy, G. (1976). Serum protein binding as a determinant of warfarin body clearance and anticoagulant effect. Clinical Pharmacology and Therapeutics, $19,552-558$. 